Children's and adolescents' gratitude expression and its association with their greatest wishes across ethnic groups in the United States

By: Elisa A. Merçon-Vargas and Jonathan R. H. Tudge

Merçon-Vargas, E. A., \& Tudge, J. R. H. (2019). Children's and adolescents' gratitude expression and its association with their greatest wishes across ethnic groups in the United States. Current Psychology, doi: 10.1007/s12144-019-00525-1

This is a post-peer-review, pre-copyedit version of an article published in Current Psychology. The final authenticated version is available online at: http://dx.doi.org/10.1007/s12144-019-00525-1.

\begin{abstract}
***(C) 2019 Springer Science+Business Media, LLC, part of Springer Nature. Reprinted with permission. No further reproduction is authorized without written permission from Springer. This version of the document is not the version of record. Figures and/or pictures may be missing from this format of the document. ***
\end{abstract}

\begin{abstract}
:
Gratitude, as a moral virtue, emphasizes reciprocity and interpersonal relations; its development involves cognitive abilities, moral understandings, and socially learned expectations. This paper aimed to explore ethnic variation in the expression of gratitude among 595 children and adolescents aged 7 to 14 (mean age $=9.71, S D=2.17$ ) in the United States (European Americans, Brazilians, Hispanics, and African Americans) and the association between gratitude and participants' wishes and age. Results indicated that Brazilians and Hispanics were more likely to use verbal (e.g., "thank you") than concrete gratitude (reciprocation without considering the benefactor's needs) than were African Americans. Older participants were less likely to express concrete than verbal and connective gratitude (reciprocation considering the benefactor's needs). Hedonistic wishes were linked to a greater likelihood of expressing verbal than connective gratitude for Brazilians compared to Hispanics. Self-oriented wishes were linked to a greater likelihood of expressing connective than verbal gratitude for Brazilians and African Americans compared to Hispanics. African Americans were less likely to express verbal than concrete gratitude when expressing self-oriented wishes than were Hispanics. This study provides evidence of developmental and cultural aspects of gratitude expression and calls attention to within-society variability.
\end{abstract}

Keywords: Gratitude | Child and adolescent development | Ethnicity | Moral development

\title{
Article:
}

Recent analyses show that most research in psychology is conducted by researchers in the United States using predominantly White and middle-class samples (Arnett 2008; Henrich et al. 2010; Nielsen et al. 2017); the research into youth gratitude is no different. U.S. samples either consist predominantly of European American participants or, when the sample is more diverse, little or 
no attention is paid to possible ethnic variations in the expression of gratitude (recent examples include Bausert et al. 2018; Kiang et al. 2018; O’Brien et al. 2018; Ramsey et al. 2018).

Although gratitude may be found and valued in various - if not all — cultures, differences and similarities in the extent to which it is valued, considered appropriate to demonstrate, and expressed should be explored (Prinz 2009; Tiberius 2004; Tudge et al. 2015b). From our point of view, failing to consider within-society variations is especially problematic when societies are ethnically, racially, and/or socio-economically complex (Tudge 2008; Tudge et al. 2000). In a multicultural society, such as the United States, the presence of diverse ethnic groups provides great opportunities to examine the ways in which cultural values impact children's development. Thus, our main goal in this paper is to explore ethnic variation in the expression of gratitude, considered as a moral virtue, among children and adolescents aged 7 to 14 in the United States.

A growing number of scholars have contributed to the discussion of gratitude as a moral virtue (see for example, Carr 2013; Gulliford et al. 2013; Kristjánsson 2013; La Taille 2000, 2018; Merçon-Vargas et al. 2018; Roberts 2016; Tudge et al. 2015b). The central point that these authors have made is that there is a distinction between being grateful for things (which has nothing to do with a moral virtue) and being grateful to people for what they have done for us. Freitas et al. (2019), Merçon-Vargas et al. (2018), and Tudge et al. (2015b) have argued that even feeling a positive emotion following receipt of some benefit may not qualify as gratitude unless accompanied by the desire to reciprocate to one's benefactors; people who typically do not want to reciprocate are failing to show moral virtue and are viewed as ungrateful. The second important argument made is that, compared with philosophers who have written about gratitude, psychologists tend to use very loose definitions of gratitude and even when their definitions are clear there is a mismatch between the conceptualization and its operationalization. For example, Froh et al. (2014) and Poelker et al. (2017) define gratitude as requiring the receipt of a benefit from a benefactor but then use a measure (the Gratitude Questionnaire-6, McCullough et al. 2002) most of whose items do not refer to benefactors (see Navarro and Morris 2018).

Thus, gratitude, as a moral virtue, involves (a) a benefactor who freely and intentionally provides a benefit to a beneficiary who, (b) feeling good about the benefit and/or the benefactor, (c) desires to reciprocate, if an appropriate opportunity presents itself, with something designed to please the benefactor. Based on this definition, the operationalization of gratitude must focus on gratitude to a benefactor for a significant benefit received. By conceptualizing gratitude in this manner, we accept that gratitude involves a positive emotion (feeling good about the benefit, the benefactor, or both) but view that emotion as not sufficient. Someone who consistently receives benefits from others and consistently feels a positive emotion, but equally consistently does nothing to benefit the benefactors despite having good opportunities to do so is rightly accused of being ungrateful rather than grateful. The desire to reciprocate to a benefactor with something he or she would value (not necessarily the fulfillment of that desire) is what transforms gratitude from a positive emotion into something virtuous (Roberts 2016; Tudge et al. 2015b). People who are grateful to others in this sense, rather than being simply grateful for the nice things they receive or for their experiences of nature, are virtuous because they take on willingly (i.e., not to fulfill some contractual obligation or because they are forced to) the moral obligation to reciprocate. 
What does it mean to consider gratitude a virtue? Virtues are lasting and morally praiseworthy dispositions, which are an essential part of a virtuous person's character. La Taille $(2000,2018)$ argued that the acknowledgment of the moral obligation to reciprocate involved in gratitude is positively regarded by most people and cultures; this, in turn, serves as a standard of a desirable character and a virtuous way in which to respond to common social situations. That is, failing to respond with gratitude when it is due (being ungrateful) is, in general, morally disapproved.

Other personal characteristics, such as being sociable or optimistic, although perhaps valued, are not virtues as they do not relate to the moral sphere.

Gratitude as a virtue is thus not the same as appreciation (see also Adler and Fagley 2005; Fagley, 2016), for which there is no moral component. We can be appreciative of the beautiful day, of the fact that we avoided being in a car crash that happened nearby, or of the fact that we have so many more nice possessions than do our friends and neighbors. However, if we are not appreciative of these things no one would accuse us of lacking virtue or being ungrateful. Ingratitude has been treated throughout history as "the king of the vices" (Emmons 2016) because it is the typical failure to reciprocate to those who have done us a kindness that is considered so heinous. Even reciprocating, but grudgingly or only under duress, is not enough to escape the charge of ingratitude - the desire to reciprocate is what allows one to say that gratitude "is the queen of the virtues" (Emmons 2016).

Thus gratitude, as a moral virtue, is not a momentary state or emotional disposition, but an enduring pattern of attitudes and actions that can only be understood within social norms and individuals' interaction with others (Annas 2011; Gulliford et al. 2013; Kristjánsson 2013; La Taille 2000, 2018; McConnell 1993; Prinz 2009; Tudge et al. 2015b). Not surprisingly, then, gratitude does not arise spontaneously; rather, becoming virtuous takes time and is developed through education, habituation, and life experiences (Annas 2011; Tudge et al. 2015b). We should expect, therefore, that when children are young they express less sophisticated types of gratitude, probably the earliest of which is learning to say "thank you" (Visser 2009). With age, experience, and encouragement, they may move to more sophisticated types of expression, including those that involve reciprocity. It is extremely unlikely, however, that many adolescents could be considered virtuously grateful; there are several aspects involved in gratitude as a virtue that demand "practical wisdom," which has yet to be fully understood by adolescents - for instance, the benefactor's intentionality and the appropriateness of reciprocation under what type of circumstances (Morgan and Gulliford 2018). Thus, this virtue does not arise unannounced in adulthood, and has its precursors in childhood and adolescence.

A developmental approach that sees gratitude as a moral virtue considers that there are less complex ways of expressing gratitude during prior developmental stages. We should also expect that different cultural groups, varying in the types of values that they hold dear, try to encourage the expression of gratitude in different ways and to different extents (Gulliford et al. 2013; Kristjánsson 2013; Morgan and Gulliford 2018; Tudge et al. 2015b; Wang et al. 2015).

\section{The development of gratitude}

Gratitude, considered as a virtue, comprises an unforced desire to reciprocate, in an appropriate manner, if and when an appropriate situation calls for it (McConnell 1993; Roberts 2016; Tudge 
et al. 2015b). Gratitude, thus, depends on the development of cognitive abilities, moral understandings, and on socially learned expectations about how to respond in situations in which gratitude is due (Baumgarten-Tramer 1938; Do Vale 2012; Freitas et al. 2011; Nelson et al. 2013; Tudge et al. 2015b). Prestes et al. (2014), using a Piagetian framework, suggested that it is through interactions with adults, and later with peers, that children learn the normative values present in their sociocultural group that regulate their relationship with others; these interactions contribute to the development of moral values.

Piaget's (1932/1965, Piaget 1965/ Piaget 1995) notion of morality poles includes a potential for gradual development from a heteronomous moral orientation (obedience and unilateral relations) to an autonomous moral sense (related to mutuality and cooperation). This development involves a decentration of the self, increasingly enabling individuals to coordinate different viewpoints and to engage in more reciprocal relationships. Heteronomous morality is one of simple and pure duty; it is objective - the child accepts (usually from adults) what must be done (the right thing to do is what conforms to adult commands; for example, when a child is told by a parent to say thank you for a gift); intentionality plays little role (Piaget, 1932/ Piaget 1965; Piaget and Inhelder 1969/1966). With the development of social cooperation and social-cognitive abilities, children's morality becomes based on mutual respect, which leads to autonomy.

Some studies have shown that gratitude involves important cognitive abilities; for instance, Nelson et al. (2013) showed that better understanding of both emotions and of others' mental states at age 3 served as a precursor to some understanding of gratitude at age 5 . There is also evidence that gratitude expression may take different complexity levels-from this perspective, less sophisticated forms (such as saying "thank you") take place prior to the development of a more sophisticated type of gratitude - one that involves reciprocating a benefit autonomously (rather than heteronomously), considering the benefactor's needs and desires (see for example, Baumgarten-Tramer 1938; Freitas et al. 2011; Tudge et al. 2015a, 2015b; Wang et al. 2015).

Baumgarten-Tramer (1938) conducted a pioneering study showing that the expression of types of gratitude was related to age. Using open-ended questions ("What is your greatest wish?" and "What would you do for the person who granted you this wish?") with Swiss 7- to 15-year-olds, she found the following: (a) verbal gratitude did not involve linear changes with age, although older children and adolescents were more likely to express it than those who were younger; (b) concrete gratitude (reciprocation, but with something that the beneficiary, rather than the benefactor, would like) was expressed more frequently by younger children; and (c) connective gratitude (reciprocation taking into consideration the wishes or needs of the benefactor) was expressed more frequently by adolescents. A fourth type of gratitude, finalistic (e.g., being an excellent student in return for a scholarship to a good university) was rarely found and only among 14- and 15-year-olds.

This measure of gratitude is a suitable operationalization of a developmental approach to gratitude as a moral virtue, given that its goal is to capture the response participants consider appropriate when a significant benefit is received. It is able to capture age-related changes, reflecting different levels of complexity in the expression of gratitude. Moreover, having participants respond about a benefactor who has provided them with their "greatest wish" 
ensures that they think about something likely to make them happy and therefore worthy of evoking gratitude. Our interest is in the types of gratitude expressed.

Thus, to the extent to which children's and adolescents' answers include a level of reciprocity that involves perspective taking and autonomously wishing to reciprocate (connective gratitude), there may be evidence of what is necessary, although not sufficient, for a virtue (a virtue involves not just expression but enactment). It is thus important to be clear that the expression of connective gratitude is not, in itself, sufficient to show that someone is virtuously grateful. However, if one fails to even feel or express connective gratitude it seems most unlikely that one would typically enact it, which is the marker of virtuous gratitude.

The concrete form of gratitude (which may involve the understanding of intentionality but shows no evidence of considering the benefactor's needs or wishes) is a self-centered type of reciprocation and may result from simply following the social norms or rules of reciprocity in some "tit-for-tat" fashion. Verbal gratitude may involve varying degrees of feelings from simple politeness to a great depth of feeling. However, saying "thank you" is something often encouraged by parents even in their very young children (Freitas et al. 2011; Visser 2009), long before they are aware of the implications of gratitude, have a theory of mind, or any sense of reciprocity for a gift. Therefore, it is possible that verbal gratitude developmentally precedes concrete gratitude.

Replications of Baumgarten-Tramer's (1938) study in the United States with children and adolescents aged 7 to 14 provided further support for her hypotheses. Specifically, younger children in the United States were more likely to express concrete gratitude and less likely to express connective gratitude than were those who were older (O'Brien et al. 2018; Tudge et al. 2015a). Age differences have also been found in other countries, with some of the results showing similar trends. For example, in the case of 7- to 14-year-old Brazilians, younger children were more likely to express concrete gratitude than were older youth (Merçon-Vargas et al. 2016; Palhares et al. 2018). Also, for same aged Guatemalan and Chinese children and adolescents, younger participants were less likely to express connective gratitude than were older ones (Liang and Kiang 2018; Poelker and Gibbons 2018; Wang et al. 2015). In the present study, we hypothesize similar trends across ethnic groups (no interaction is expected), in which older children and adolescents will be more likely to express connective and less likely to express concrete gratitude than will younger children.

\section{Gratitude and its association to wishes}

Given our conceptualization and operationalization of gratitude, in the present study children's and adolescents' greatest wishes were used to set up a meaningful (albeit hypothetical) benefit. As noted earlier, gratitude, in contrast to appreciation, involves gaining some valued benefit from a benefactor. Unlike other measures that have been used to assess gratitude, which typically neither mention a benefactor nor consider reciprocation, the measure we use specifically asks participants to think about something they would really like and then requires them to say what, if anything, they would do for the benefactor who provided them with that benefit. Children and adolescents are likely to vary quite considerably in the type of benefit that they would value; asking them about their "greatest wish" in some ways produces a level playing field in which all 
respondents are considering something that they equally value. However, any particular goal or value exists within a broader system of goals and values (Dittmar et al. 2014; Freitas et al. 2016). Because our participants' wishes reflected different values, it is important to assess the extent to which these different values relate to the type of gratitude they expressed. It is important to recognize, however, that children's and adolescents' values are still in the process of development (Freitas et al. 2016).

Children's and adolescents' wishes for things that would provide them with immediate pleasure represented hedonistic values. These included wishes for material things (e.g., "I want an iPhone"), money, immediate fame by being a YouTube "star," etc. Wishes that involved a future perspective for oneself were considered self-oriented values, and included academic and professional aspirations (e.g., "I wish to become a doctor"), wishes for their own well-being (e.g., "to have a happy life"), etc. Finally, wishes that involved others represented socialoriented values, which included wishes for the well-being of the family, friends, and society (e.g., "I wish for less violence") or the entire world (e.g., "I want there to be peace on earth").

Therefore, children's and adolescents' greatest wishes reflected their values whether they were for something that provided them with immediate pleasure, for their future individual well-being, or for the well-being of others. In other words, whereas hedonism is linked to immediate gratification for oneself, self- and social-oriented wishes involve an ability to think long-term and autonomously. Autonomy is reflected in self-directedness (e.g., being able to succeed for oneself) and in the spontaneous sense of benevolence toward others (not because others told them that they needed to reciprocate). However, self- and social-oriented wishes differ in relation to whether they are focused on themselves or on others.

Previous research provided some support for the notion that gratitude is inversely related to hedonistic values and positively related to social-oriented values for 7- to 14-year-olds. Specifically, Tudge et al. (2015a) found a significant inverse association between connective gratitude and hedonistic wishes among children and adolescents in the United States. Moreover, other results indicated that concrete gratitude was positively associated with hedonistic wishes, and connective gratitude was positively associated with social-oriented wishes among Brazilian and Chinese children and adolescents (e.g., Freitas et al. 2016; Liang and Kiang 2018; Mendonça et al. 2018; Palhares et al. 2018). Based on that, in the present study, we hypothesized that participants across ethnic groups who expressed hedonistic wishes would be more likely to express concrete than connective gratitude. In contrast, participants who expressed socialoriented wishes would be more likely to express connective than concrete gratitude. Given the lack of studies addressing group differences, we expected a similar trend across groups (no interaction was expected).

\section{Cultural variations in gratitude expression}

Despite the lack of studies examining variations in gratitude across ethnic groups in the United States, there is some evidence of cross-cultural differences in the expression of gratitude. For instance, 7- to 14-year-olds in the United States were more likely to express concrete gratitude than were same-age youth in China, Guatemala, Russia, South Korea, and Turkey. They were also less likely to express connective gratitude than were children and adolescents in China, 
South Korea, Russia, and Turkey. Moreover, compared to children and adolescents in Latin American cultures (Guatemala and Brazil), participants in the United States were less likely to express verbal gratitude (Mendonça et al. 2018). These cultural differences are likely related to variations in cultural values, such as relatedness (feelings of connectedness with others), which is more valued in non-Western societies (such as Asian and Latin American cultures) and autonomy (thinking and acting in a self-directed way), more valued in Western cultures, such as the United States (Hofstede 2001; Kağıtçıbaşı 2007).

Considering the fact that large societies such as the United States are socioculturally heterogeneous, and that values are influenced by the sociocultural group within which people are raised, scholars should also pay attention to within-society cultural differences. This is likely to be particularly the case for children from immigrant backgrounds, given that some of their connectedness values may be maintained (Stein et al. 2014), while also ascribing to some of the mainstream cultural values of the host culture, such as autonomy (Kağıtçıbaşı 2003). Research in the United States has also pointed to important differences in cultural values across ethnic groups. For instance, Coon and Kemmelmeier (2001), using a meta-analytic approach, showed that, compared to European Americans, Asian Americans and African Americans scored higher in collectivism. Interestingly, African Americans also scored higher in individualism than did European Americans.

Considering both the cross-cultural studies' findings suggesting that cultures placing a greater emphasis on relatedness may foster the expression of connective gratitude and the findings that ethnic and immigrant sociocultural groups in the United States are more likely to value connectedness with others, we can expect differences in gratitude expression of children and adolescents from different ethnic backgrounds in the U. S. Based on that, we hypothesize that participants from underrepresented ethnic groups in the United States, such as African Americans, Hispanics, and Brazilian immigrants, will be more likely to express connective rather than concrete gratitude than will European American children and adolescents. Also, we expect that Hispanic and Brazilian immigrant participants will be more likely to express verbal gratitude than will European and African Americans (see for example, Mendonça et al. 2018; Palhares et al. 2018; Poelker and Gibbons 2018).

\section{Method}

\section{Participants}

This study is part of a larger cross-cultural project that includes data from participants in six countries (Brazil, China, Turkey, Russia, South Korea, and the United States). For this study, only data from participants living in the United States were included. The decision to not include children and adolescents in other countries were based on the fact that some of our previous work has extensively addressed cross-cultural variations [e.g., Mendonça et al. 2018]. Also, comparing ethnically diverse samples from different countries (such as Brazil and the United States) in a culturally sensitive manner would be complicated; thus, we decided to focus on variability within the United States (for socioeconomic variability within Brazil see MerçonVargas et al. 2016). 
The present sample included a total of 595 participants (aged 7 through 14) $-38.32 \%$ were European Americans (mean age $=9.94, S D=2.27,59.2 \%$ girls), 18.49\% Brazilians (mean age $=9.49, S D=2.10,57.27 \%$ girls), $18.49 \%$ Hispanics (mean age $=9.45, S D=2.02,47.3 \%$ girls), 24.71\% African Americans (mean age =9.69, $S D=2.16,47.6 \%$ girls). Asian American children and adolescents were not included in the analyses due to the small sample size $(n=42)$. Table 1 shows the demographic characteristics of the sample. Some of the children's $(n=46)$ answers were missing because they were unreadable, participants left the answers blank, or children were not in the school at the time of data collection. Missing data were handled by listwise deletion, given its relatively small number (not affecting the statistical power of our analyses) and because our main dependent variable is categorical (estimating statistics and imputing missing data are available on SPSS only for quantitative variables).

Table 1. Demographic Information

\begin{tabular}{|llllll|}
\hline & $\begin{array}{l}\text { African } \\
\text { Americans }\end{array}$ & $\begin{array}{l}\text { European } \\
\text { Americans }\end{array}$ & Hispanics & $\begin{array}{l}\text { Brazilian in the } \\
\text { United States }\end{array}$ & Overall \\
\hline Age (mean and $S D)$ & $9.69(2.16)$ & $9.94(2.27)$ & $9.45(2.02)$ & $9.49(2.10)$ & $9.71(2.17)$ \\
Gender (girls) & $70(47.6 \%)$ & $135(59.2 \%)^{\mathrm{a}}$ & $52(47.3 \%)$ & $63(57.3 \%)$ & $320(53.9 \%)$ \\
Parental Education & & & & \\
Elementary School & $4(0.9 \%)$ & $1(0.4 \%)$ & $38(34.6 \%)$ & $7(6.4 \%)$ & $50(8.4 \%)$ \\
Some High School & $7(4.8 \%)$ & $4(1.8 \%)$ & $23(20.9 \%)$ & $4(3.6 \%)$ & $38(6.4 \%)$ \\
High School & $13(8.8 \%)$ & $12(5.3 \%)$ & $19(17.3 \%)$ & $20(18.2 \%)$ & $64(10.8 \%)$ \\
Some College & $38(25.9 \%)$ & $19(8.3 \%)$ & $8(7.3 \%)$ & $11(10.0 \%)$ & $76(12.8 \%)$ \\
College & $24(16.3 \%)$ & $69(30.3 \%)$ & $1(0.9 \%)$ & $21(19.1 \%)$ & $115(19.3 \%)$ \\
M.S. or Equivalent & $4(2.7 \%)$ & $30(13.2 \%)$ & $1(0.9 \%)$ & $37(33.6 \%)$ & $72(12.1 \%)$ \\
PhD & $1(0.7 \%)$ & $20(8.8 \%)$ & $0(0 \%)$ & $1(0.9 \%)$ & $22(3.7 \%)$ \\
Missing & $56(38.1 \%)$ & $73(32.0 \%)$ & $20(18.2 \%)$ & $9(8.2 \%)$ & $158(26.6 \%)$ \\
$n$ & 147 & 228 & 110 & 110 & 595 \\
\hline
\end{tabular}

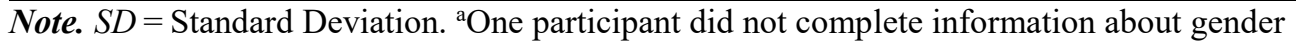

Participants were recruited through the selection of schools in neighborhoods with different levels of ethnic composition and affluence in a city in the southeast United States (a diverse range of educational backgrounds was not found among Hispanic participants, given that the majority were in the schools in the less affluent neighborhoods). Brazilian immigrants were recruited from three different states in the east of the United States; a diverse sample in relation to SES was obtained through both contact with institutions (such as after-school programs, churches, and language schools) in areas with higher concentrations of Brazilians and by snowballing.

Approximately $90 \%$ of the Brazilian immigrant families reported speaking Portuguese as the first language at home, and 37.3\% used English as the second language. Of the parents completing the consent, $96.4 \%$ were born in Brazil, as were $87.3 \%$ of their spouses (from whom we had information); however, $72.7 \%$ of children and adolescents were born in the United States. Only $10.9 \%$ of the participants chose to complete the questionnaires in Portuguese. The average time Brazilian families had lived in the U. S. was 11.58 years $(S D=6.22)$.

For the Hispanics, $69.1 \%$ of the sample reported speaking Spanish as the primary language of the household. Most parents were born in Mexico (61.8\%), followed by the United States (15.5\%); 
about $7.2 \%$ of the parents were born in other Central America countries, such as Guatemala, El Salvador, and Honduras; $50.9 \%$ of their spouses from whom we had information were born in Mexico. Most children and adolescents were born in the United States (82.7\%), with only 3.6\% being born in Mexico; $2.8 \%$ of participants completed the questionnaire in Spanish. No information was collected from this group regarding time living in the United States or their generation, given that the data collection with this group started before revisions were made to the demographic instrument.

\section{Measures}

The first two questions in the Wishes and Gratitude Survey (WAGS: Freitas et al. 2008, adapted from Baumgarten-Tramer 1938) were used in the present study to assess children's and adolescents' greatest wish and gratitude expression. This measure comprises four open-ended questions that aim to assess different ways participants would hypothetically express gratitude (e.g., verbally, concretely, or connectively) to a benefactor who they believed would grant their greatest wish. The questions included in the WAGS are: (a) "What is your greatest wish?" (b) "What would you do for the person who granted you this wish?" (c) "Is there anything else you should do?" and (d) "Who is this person?"

The types of gratitude expression derived from the second question of the WAGS, and were initially defined by Baumgarten-Tramer (1938): (a) verbal (e.g., "Say thank you" or "I would be forever grateful"), (b) concrete ("Give them a hug" or "Give him/her a cookie"), (c) connective ("I would ask them how I could help them, and do what I am capable of to help that person" or "Anything they want"), (d) finalistic ("If I go to college, I will be the best student ever", (e) selfsufficient ("Nobody can help me get the things I want; only I can do that"), and (f) other. The distinction between concrete and connective gratitude is that in the case of the former there is no evidence that the benefactor wants or needs what the participant is offering (the assumption seems to be that reciprocating with something that the child likes is an adequate response to being granted one's greatest wish). By contrast, to be coded as connective gratitude, there has to be evidence that the participant is considering the benefactor's wishes or needs, or at least willing to do so when reciprocating — "I would do anything I can to help them."

Given that just a small proportion of participants expressed the three last categories of gratitude ( $0.2 \%$ finalistic, $0.3 \%$ self-sufficient, and $4.4 \%$ other), only the three first main types of gratitude were entered as dependent variables in the analyses (a total of 29 participants were therefore not included in the analyses). Our previous work using Latent Class Analysis with the main types of gratitude as profile indicators showed that types of gratitude represented the main profiles of gratitude expression by itself (see Merçon-Vargas 2017). In line with that, in the present sample, only $11.6 \%$ of participants expressed more than one type of gratitude concomitantly. We, therefore, decided to enter each of these types of gratitude in a single categorical variable with three levels; if participants had expressed more than one type of gratitude, the highest level of gratitude was considered, as follow: $1=$ verbal, $2=$ concrete, and $3=$ connective. A second judge coded $24 \%$ or more of participants' answers. The intercoder reliabilities (Kappa) were .89 for verbal, .91 for concrete, and .86 for connective gratitude. 
Children's and adolescents' greatest wishes were derived from the answers to the first question in the WAGS and were coded as in previous research (Freitas et al. 2016; Tudge et al. 2015a): (a) hedonism (material, monetary, fame, and fantasy/magical wishes; e.g., "I wish for a million dollars" or "to have nerf guns"); (b) a self-oriented wish (personal future-oriented well-being, academic, and career wishes; e.g., "I become a professional soccer player" or "I get into Stanford"); (c) a social-oriented wish (wishes for the family or others' well- being; e.g., "for my parents to become citizens of America" and "help the elderly and homeless"); and (d) other $(3.53 \%)$. Each of these three main types of wish was dummy coded to reflect whether participants expressed it or not $(1=$ Yes, $2=$ No) and were entered as independent variables (the percentage of participants expressing these wishes may exceed 100 as some expressed more than one type of wish). A second judge coded $24 \%$ or more of participants' answers; the intercoder reliabilities (Kappa) were .92 for hedonism, .90 for self-oriented wishes, and .92 for socialoriented wishes.

Table 2 displays the frequencies of gratitude and wishes types. Other variables entered as predictors included ethnic group (African Americans; European Americans; Hispanics; Brazilian immigrants), participants' age (from 7 to 14), and gender (control variable). We decided to control for gender based on findings from the United States indicating that girls were less likely to express concrete gratitude than were boys (O'Brien et al. 2018).

Table 2. Frequency and Percentage of Gratitude and Wishes

\begin{tabular}{|llllll|}
\hline & African Americans & European Americans & Hispanics & \multicolumn{2}{l|}{ Brazilians in the U. S. Overall } \\
\hline Wishes & & & & & \\
Hedonism & $78(53.1 \%)$ & $84(36.8 \%)$ & $62(56.4 \%)$ & $49(44.5 \%)$ & $273(45.9 \%)$ \\
Self-oriented & $61(41.5 \%)$ & $104(45.6 \%)$ & $37(33.6 \%)$ & $50(45.5 \%)$ & $252(42.4 \%)$ \\
Social-oriented & $12(8.2 \%)$ & $37(16.2 \%)$ & $8(7.3 \%)$ & $15(13.6 \%)$ & $72(12.1 \%)$ \\
Gratitude & & & & & \\
Verbal & $30(20.4 \%)$ & $49(21.5 \%)$ & $31(28.2 \%)$ & $32(29.1 \%)$ & $142(23.9 \%)$ \\
Concrete & $64(43.5 \%)$ & $78(34.2 \%)$ & $32(29.1 \%)$ & $34(30.9 \%)$ & $208(35.0 \%)$ \\
Connective & $48(32.7 \%)$ & $89(39.0 \%)$ & $36(32.7 \%)$ & $43(39.1 \%)$ & $216(36.3 \%)$ \\
Finalistic & $1(0.7 \%)$ & $0(0 \%)$ & $0(0 \%)$ & $0(0 \%)$ & $1(0.2 \%)$ \\
Self-sufficient & $0(0 \%)$ & $2(0.9 \%)$ & $0(0 \%)$ & $0(0 \%)$ & $2(0.3 \%)$ \\
Other & $4(2.7 \%)$ & $10(4.4 \%)$ & $11(10.0 \%)$ & $1(0.9 \%)$ & $26(4.4 \%)$ \\
$N$ & 147 & 228 & 110 & 110 & 595 \\
\hline
\end{tabular}

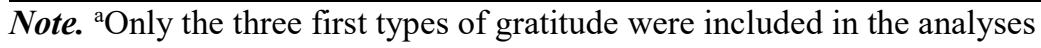

Procedure

Data collection was conducted in two parts - the first consisted of in-school surveys (or afterschool institutions for Brazilians) and the second of in-home interviews. Only data from the first part was used in this study. Children and adolescents in the target schools and institutions were given recruitment letters and consent forms to take home to their parents/guardians for school- or institution-based data collection. A demographic questionnaire (including information such as child's age, parents' and child's place of birth, language spoken at home, parental level of education, job, etc.) was sent home together with the letter of consent. 
Parents were asked to indicate on the consent forms whether they provided consent for themselves and their child's participation in Part 1 and 2 and return it to the school or institution. A small monetary incentive was given to teachers or instructors for each returned permission letter, regardless of parents' agreement for their children to participate. Children and adolescents whose parents returned signed consent forms were themselves asked to give consent to participate and completed an in-school or institution survey that included measures of gratitude and wishes. For the Brazilians recruited through snowballing, Parts 1 and 2 occurred in-home on the same day, using a combined consent form.

\section{Analytical procedures}

Based on our assumption that the three types of gratitude are developmentally different from each other, we ran multinomial logistic regression analyses in SPSS (version 23) to test our hypotheses. Connective gratitude was first used as the category of reference for the dependent variable (exploring whether participants who expressed connective gratitude differed from those expressing concrete and verbal gratitude); we then inverted the category of reference to be verbal gratitude (exploring whether participants who expressed verbal gratitude differed from those expressing concrete gratitude). In the first analyses, we included ethnicity, age, and the three types of wishes as predictors; ethnic groups were alternated as the reference category to allow comparisons among all groups. Next, we entered interaction terms between ethnic group and age and ethnic group and each type of wish, one at a time. Only significant interactions were interpreted. Separate analyses with each ethnic group were conducted to further explore relations between gratitude expression and the predictors.

Preliminary results indicated that there was no significant effect of parental educational level (parents with less than a college degree versus parents with a college degree or higher) on gratitude expression, controlling for ethnicity. We, therefore, decided not to include this variable in the model. Although we believe this is an extremely important variable, the decision not to include parental educational level in the model was further based on the amount of missing data and the lack of variability of educational level in some groups, especially the Hispanics (only 2 parents had college degree or more, as can be seen in Table 1). Also, ANOVA tests indicated no difference in the mean age of participants across ethnic groups.

\section{Results}

Gratitude expression across ethnic groups

Results indicated that the relative odds ratio of expressing concrete rather than verbal gratitude were respectively 2.03 and 2.28 times lower for Brazilian and Hispanic immigrants in comparison to African American children and adolescents

(Brazilians: $B=-.707, p=.037, e^{b}=.493$, CI [.254, .958];

Hispanics: $B=-.826, p=.016, e^{b}=.438$, CI $\left.[.223, .858]\right)$. Contrary to our hypothesis, no other significant group difference was found. In particular, our hypothesis that Hispanics and Brazilian immigrants would be more likely to express verbal gratitude than other groups was only partly supported. However, the hypothesis that European American participants would be less likely to 
express connective gratitude than would children and adolescents in other ethnic groups was not supported.

Age-related patterns in gratitude expression

In accordance with our hypothesis, the findings indicated an overall age effect in which the relative odds ratio for one-unit increase in age was 1.29 times lower for expressing concrete rather than connective gratitude $\left(B=-.257, p=.000, e^{b}=.773, \mathrm{CI}[.696, .859]\right)$. This pattern was confirmed across groups in the separate analyses (African

Americans: $B=-.278, p=.009, e^{b}=.758$, CI [.616, .932]; European

American: $B=-.242, p=.002, e^{b}=.785$, CI $[.669, .922]$;

Hispanics: $B=-.376, p=.029, e^{b}=.686$, CI [.490, .962];

Brazilians: $B=-.292, p=.044, e^{b}=.747$, CI $\left.[.562, .993]\right)$.

Although not expected, the relative odds ratio for one-unit increase in age was 1.17 times lower for expressing concrete rather than verbal gratitude $\left(B=-.159, p=.006, e^{b}=.853\right.$, CI [.760, .956]). However, when considering the results separately for each ethnic group, this age effect was not significant (although it was close to significance for African Americans $(p=.086)$, Hispanics $(p=.075)$, and Brazilians $(p=.079)$, explaining, perhaps, the reason why it was significant for the overall analyses). As hypothesized, no significant interaction between age and ethnicity was found.

Table 3. Odds Ratio for Multinominal Logistic Regression Models

\begin{tabular}{|c|c|c|c|c|c|c|}
\hline & \multicolumn{2}{|c|}{ Concrete vs. Verbal ${ }^{a}$} & \multicolumn{2}{|c|}{ Concrete vs. Connective ${ }^{\mathrm{a}}$} & \multicolumn{2}{|c|}{ Verbal vs. Connective ${ }^{a}$} \\
\hline & Odds ratio & $95 \% \mathrm{CI}$ & Odds ratio & $95 \%$ CI & Odds ratio & $95 \%$ CI \\
\hline Age & $0.85^{*}$ & {$[0.76,0.96]$} & $0.77 * *$ & {$[0.70,0.86]$} & $0.91 \dagger$ & {$[0.82,1.01]$} \\
\hline Gender & 1.37 & {$[0.88,2.14]$} & 1.20 & {$[0.79,1.81]$} & 0.87 & {$[0.56,1.36]$} \\
\hline Hedonism & 0.92 & {$[0.38,2.21]$} & $1.95 \dagger$ & {$[0.89,4.27]$} & $2.12 \dagger$ & {$[0.90,5.02]$} \\
\hline Self-oriented wish & 0.59 & {$[0.24,1.42]$} & 1.02 & {$[0.46,2.25]$} & 1.73 & {$[0.73,4.10]$} \\
\hline Social-oriented wish & 0.56 & {$[0.19,1.61]$} & 0.58 & {$[0.23,1.48]$} & 1.05 & {$[0.41,2.69]$} \\
\hline European Americans ${ }^{\mathrm{b}}$ & 1.65 & {$[0.89,3.05]$} & 1.37 & {$[0.77,2.45]$} & 0.84 & {$[0.47,1.50]$} \\
\hline African Americans ${ }^{\mathrm{b}}$ & $2.03 *$ & {$[1.04,3.94]$} & $1.73 \dagger$ & {$[0.93,3.21]$} & 0.85 & {$[0.44,1.64]$} \\
\hline Hispanics $^{\mathrm{b}}$ & 0.89 & {$[0.44,1.80]$} & 1.03 & {$[0.52,2.06]$} & 1.16 & {$[0.59,2.29]$} \\
\hline African Americans ${ }^{\mathrm{c}}$ & 1.23 & {$[0.69,2.21]$} & 1.26 & {$[0.75,2.11]$} & 1.02 & {$[0.57,1.84]$} \\
\hline Hispanics $^{\mathrm{c}}$ & $0.54 \dagger$ & {$[0.29,1.02]$} & 0.75 & {$[0.41,1.38]$} & 1.39 & {$[0.76,2.57]$} \\
\hline Hispanics $^{\mathrm{d}}$ & $0.44 *$ & {$[0.22,0.86]$} & 0.60 & {$[0.32,1.13]$} & 1.36 & {$[0.70,2.67]$} \\
\hline \multicolumn{7}{|l|}{ Significant Interactions } \\
\hline Hedonism $^{*}$ Hispanics $^{\mathrm{b}}$ & - & - & - & - & $0.15^{*}$ & {$[0.04,0.63]$} \\
\hline Self $*$ Hispanics $^{\mathrm{b}}$ & - & - & - & - & $4.56^{*}$ & {$[1.16,18.06]$} \\
\hline Self* Hispanics ${ }^{\mathrm{d}}$ & $0.14 *$ & {$[0.03,0.61]$} & - & - & $5.69^{*}$ & {$[1.41,22.89]$} \\
\hline
\end{tabular}

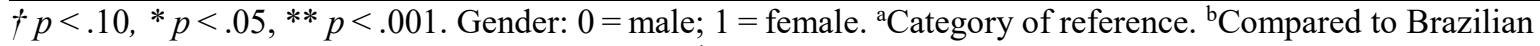
immigrants. ${ }^{c}$ Compared to European Americans. ${ }^{\mathrm{d} C o m p a r e d ~ t o ~ A f r i c a n ~ A m e r i c a n s ~}$

Associations between gratitude and wishes across ethnic groups

Contrary to what we had hypothesized, none of the types of wishes were statistically significant for any type of gratitude. In contrast to what we had expected, some interactions terms between ethnicity and wishes were found to be significant. Compared to Hispanics, Brazilian immigrants 
expressing hedonistic wishes were 6.49 times less likely to respond with connective rather than verbal gratitude $\left(B=-1.868, p=.009, e^{b}=.154\right.$, CI $\left.[.038, .627]\right)$. The opposite was found for self-oriented wishes, in which Brazilian immigrants expressing this type of wish were 4.58 times more likely to express connective rather than verbal gratitude $\left(B=1.521, p=.030, e^{b}=4.576, \mathrm{CI}\right.$ $[1.159,18.063])$. Also, compared to Hispanics, African American participants expressing selforiented wishes were 5.69 times more likely to express connective rather than verbal gratitude $\left(B=1.739, p=.014, e^{b}=5.689, \mathrm{CI}[1.414,22.888]\right)$ and were 7.19 times less likely to express verbal than concrete gratitude $\left(B=-1.972, p=.009, e^{b}=.139\right.$, CI $\left.[.032, .611]\right)$. The summary of the results can be seen in Table 3 .

\section{Discussion}

This study brings a unique contribution to the literature by addressing gratitude development across diverse ethnic groups in the United States. As is true of most psychology studies in the United States, most of the research to date conducted on youth gratitude has used predominantly White middle-class samples or, in the case of more diverse samples, has not focused on ethnic/racial or social-class variability (Arnett 2008; Henrich et al. 2010). Equally important, this study assesses gratitude as related to a character virtue, clearly different from treating the concept as either a positive emotion or as a unidimensional construct differing only in degree (i.e., scoring higher or lower). Instead, youth responses to obtaining-hypothetically at leasttheir greatest wish can be reliably differentiated into three types, one of which (connective gratitude) seems to satisfy the minimum requirements for gratitude as a virtue. Furthermore, it advances the understanding of how values may impact gratitude by assessing the associations between gratitude expression and hedonistic, self-, or social-directed wishes. The comprehension of how gratitude develops across cultural groups living in the same society and what contributes to this development may help culturally sensitive interventions designed to encourage gratitude in children and adolescents.

Regarding group differences, in contrast to what we expected, participants from underrepresented groups, deemed to be more likely to value relatedness (e.g., Coon and Kemmelmeier 2001), did not differ in their expression of connective gratitude from European Americans. Unfortunately, we did not assess relatedness directly, so we could only speculate on the association between connective gratitude and relatedness. However, it is possible that, overall, the development of social-cognitive abilities allows older children and adolescents in all groups to think from others' perspective (e.g., Baumgarten-Tramer 1938; Do Vale 2012; Freitas et al. 2011; Nelson et al. 2013; Tudge et al. 2015b). Also, the fact that we did not find any significant differences in gratitude expression between European Americans and the other ethnic groups, as we had expected, should be better explored. Perhaps there are other important variables that should be considered when thinking of gratitude expression among some groups, such as parents' educational level (giving our limitation of getting a broad range of parents' education for some groups and the missing data, we could not explore this issue in the present paper).

In contrast, we did find support for our hypothesis that children and adolescents from Latin American backgrounds (both Hispanics and Brazilians) were more likely to use verbal gratitude than concrete gratitude, at least in comparison to African Americans. Although the reasons for 
that need to be better explored, it is possible that verbally expressing thanks in Latin cultures is linked to a social convention, while reciprocating with something concrete is more valued among other cultures (such as African Americans) - especially among younger children (Mendonça et al. 2018). This also suggests that Hispanic and Brazilian immigrant children and adolescents internalize and maintain some cultural practices related to gratitude from their culture of origin, despite exposure to mainstream host cultural values (Kağıtçıbaşı 2003).

Importantly, the findings provided further support for age-related patterns of gratitude expression, in which older children and adolescents across groups were more likely to express connective than concrete gratitude (e.g., Baumgarten-Tramer 1938; Freitas et al. 2011; O'Brien et al. 2018; Tudge et al. 2015a; Wang et al. 2015). These results strengthen the claim that gratitude involves the development of cognitive skills, such as being able to consider others' perspectives and think autonomously. That is, simpler forms of reciprocation (such as a more self-centered way to express gratitude) precedes the ability to express gratitude connectively. This finding has implications, for example, for expectations and socialization practices, which should be developmentally appropriate.

Thus, although it may be appropriate to expect younger children to write "thank you" notes or reciprocate with something concrete (like a toy), in the case of older children and adolescents, parents should reinforce reciprocation taking into account the benefactor's perspective. That is not to say, however, that only older children and adolescents should be encouraged to think of others. For instance, when a child receives a present, parents could encourage her or him from a young age to think about the effort it took the benefactor to get the present; if an opportunity arises to return the favor, parents should encourage the child to think of something the benefactor would like to receive (e.g., "your aunt likes to swim, what do you think about getting her nice goggles?").

Contrary to what we had expected, the relation between wishes and gratitude varied across ethnic groups. For instance, expressing hedonistic wishes was linked to a lesser likelihood of expressing connective than verbal gratitude for Brazilians in comparison to Hispanics. This finding supports the view that hedonistic values hamper reciprocation involving perspective taking, at least for Brazilians (Freitas et al. 2016; Liang and Kiang 2018; Mendonça et al. 2018; Palhares et al. 2018). This result may also suggest that, for Hispanics, there are other cultural values strengthening the expression of connective gratitude despite wishing for hedonistic things. A good strategy to foster the development of connective gratitude among Brazilians would be to discourage wishes related to immediate pleasure and encourage long term wishes for oneself and others.

In addition, self-oriented wishes were linked to a greater likelihood of expressing connective than verbal gratitude for Brazilians and African Americans compared to Hispanics. Also, African Americans were less likely to express verbal rather than concrete gratitude when expressing selforiented wishes than were Hispanics. Overall, it seems that self-oriented and hedonistic wishes work inversely for the expression of connective gratitude among Brazilian immigrants and Hispanics, with the first triggering greater perspective-taking among Brazilian immigrants and the latter among Hispanics. Although the results for African Americans are similar to those for Brazilian immigrants (in comparison to Hispanics), this seems to be actually linked to a lesser 
likelihood of expressing verbal gratitude in general for African Americans (Mendonça et al. 2018). These results suggest that Hispanic children and adolescents wishing for academic or personal well-being for themselves could be encouraged to think of others who may have helped them to achieve their aspirations, as well as thinking of ways to reciprocate to these people (according to their needs and wishes).

Even though this study contributes to the understanding of gratitude expression across ethnic groups in the United States, some limitations should be addressed in future research. First, in the present study, cultural values were used as a basis to understand group differences and similarities; however, it is critical to empirically assess the mechanisms involved in gratitude development, such as how parents' values and socialization practices may influence their children's gratitude. Our previous work has provided some support that parents' heteronomous values (linked to obedience) were related to the verbal expression of gratitude among Hispanics in the United States Merçon-Vargas 2017.

In addition, it is important to reiterate that we would not expect children and adolescents in the age range of the present sample to have fully developed gratitude as a virtue. The expression of connective gratitude may be necessary but is certainly not sufficient for youth to become virtuously grateful. That is, connective gratitude is an important step toward gratitude as a virtue, but it does not fully represent gratitude as a virtue. For example, the behavioral component (whether someone actually acts as his or her expression suggests) is necessary for any virtue, and for someone to be considered virtuously grateful they should typically act appropriately. Whether children act as they say they would act is clearly something that should be explored in future research. Moreover, there are several aspects involved in gratitude as a virtue that demand "practical wisdom," which has yet to be fully understood by adolescents - for instance, the benefactor's intentionality and the appropriateness of reciprocation under what type of circumstances (Morgan and Gulliford 2018).

It is also necessary to point out that the sample sizes were fairly small, especially when considering the number of participants expressing each type of gratitude and wishes. Thus, these results should be interpreted with caution (this is reflected, for example, in large confidence intervals) and need to be replicated with larger groups. Moreover, there is a need to include children and adolescents from more diverse socioeconomic backgrounds, especially Hispanics, in order to better capture the role of parental educational level on gratitude expression. Finally, this study is cross-sectional, allowing only inferences of causality. Future studies should address whether children's and adolescents' expressions of gratitude change longitudinally, as well as consider possible factors and mechanisms contributing to this development (e.g., personal characteristics, SES, parental socialization practices, etc.).

In sum, the present study contributes to the comprehension of gratitude by providing evidence of developmental and cultural aspects of its expression. Moreover, it shows how children's and adolescents' greatest wish may impact the way they express gratitude (especially for some ethnic groups). The results presented here may serve as a basis to strategies aimed to raise grateful children, such as encouraging them to focus on the benefactor rather than on the benefit itself and to think from other's points of view. These strategies should take into account cognitive abilities, as well as appropriate social norms of each ethnic group. Lastly, both the cultural 
differences and similarities showed here should call attention to the importance of considering within-society variability.

Acknowledgments. This research was supported by the John Templeton Foundation (Grant 43510 to Jonathan R. H. Tudge, PI) and Coordenação de Aperfeiçoamento de Pessoal de Nível Superior (Capes; BEX 0959/12-0 to Elisa A. Merçon-Vargas).

Conflict of Interest. On behalf of all authors, the corresponding author states that there is no conflict of interest.

Ethical Approval. All procedures performed in studies involving human participants were in accordance with the ethical standards of the institutional research committee (having received IRB approval from the University of North Carolina at Greensboro) and with the 1964 Helsinki declaration and its later amendments or comparable ethical standards.

Informed Consent. Informed consent was obtained from all individual participants and their parents included in the study.

\section{References}

Adler, M. G., \& Fagley, N. S. (2005). Appreciation: Individual differences in finding value and meaning as a unique predictor of subjective well-being. Journal of Personality, 73, 79114. https://doi.org/10.1111/j.1467-6494.2004.00305.x.

Annas, J. (2011). Intelligent virtue. Oxford: Oxford University Press.

Arnett, J. J. (2008). The neglected 95\%: Why American psychology needs to become less American. American Psychologist, 63, 602-614. https://doi.org/10.1037/0003066X.63.7.602.

Baumgarten-Tramer, F. (1938). "Gratefulness" in children and young people. The Journal of Genetic Psychology, 53, 53-66. https://doi.org/10.1080/08856559.1938.10533797.

Bausert, S., Froh, J. J., Bono, G., Rose-Zornick, R., \& Rose, Z. (2018). Gratitude in adolescence: Determinants and effects on development, prosocial behavior, and well-being. In J. R. H. Tudge \& L. B. L. Freitas (Eds.), Developing gratitude in children and adolescents (pp. 135-153). London: Cambridge University Press.

Carr, D. (2013). Varieties of gratitude. Journal of Value Inquiry, 47(1-2), 1728. https://doi.org/10.1007/s10790-013-9364-2.

Coon, H. M., \& Kemmelmeier, M. (2001). Cultural orientations in the United States: (re) examining differences among ethnic groups. Journal of Cross-Cultural Psychology, 32, 348-364. https://doi.org/10.1177/0022022101032003006.

Dittmar, H., Bond, R., Hurst, M., \& Kasser, T. (2014). The relationship between materialism and personal well-being: A meta-analysis. Journal of Personality and Social Psychology, 107, 879-924. 
Do Vale, L. G. (2012) Desenvolvimento moral: A generosidade relacionada à justiça e à gratidão sob a ótica das crianças (Unpublished master thesis). Universidade de São Paulo, São Paulo.

Emmons, R. A. (2016). Is gratitude queen of the virtues and ingratitude king of the vices? In D. Carr (Ed.), Perspectives on gratitude: An interdisciplinary approach (pp. 141-153). New York: Routledge.

Fagley, N. S. (2016). The construct of appreciation: It is so much more than gratitude. In D. Carr (Ed.), Perspectives on gratitude: An interdisciplinary approach (pp. 70-84). New York: Routledge.

Freitas, L. B. L., Merçon-Vargas, E. A., Palhares, F., \& Tudge, J. R. H. (2019). Assessing variations in the expression of gratitude in youth: A three-cohort replication in southern Brazil. Current Psychology. https://doi.org/10.1007/s12144-019-00334-6.

Freitas, L. B. L., Pieta, M. A. M., \& Tudge, J. R. H. (2011). Beyond politeness: The expression of gratitude in children and adolescents. Psicologia: Reflexão e Crítica, 24, 757764. https://doi.org/10.1590/S0102-79722011000400016.

Freitas, L. B. L., Tudge, J. R. H., \& McConnell, T. (2008). The wishes and gratitude survey (Unpublished Questionnaire). Greensboro, NC. (Adapted and expanded from Baumgarten-Tramer, 1938).

Freitas, L. B. L., Tudge, J., Palhares, F., \& Prestes, A. C. (2016). Relações entre desenvolvimento da gratidão e tipos de valores em jovens. Psico-USF, 21, 1324. https://doi.org/10.1590/1413-82712016210102.

Froh, J. J., Bono, G., Fan, J., Emmons, R. A., Henderson, K., Harris, C., Leggio, H., \& Wood, A. M. (2014). Nice thinking! An educational intervention that teaches children to think gratefully. School Psychology Review, 43(2), 132-152.

Gulliford, L., Morgan, B., \& Kristjánsson, K. (2013). Recent work on the concept of gratitude in philosophy and psychology. Journal of Value Inquiry, 47, 285-

317. https://doi.org/10.1007/s10790-013-9387-8.

Henrich, J., Heine, S. J., \& Norenzayan, A. (2010). The weirdest people in the world? Behavioral and Brain Sciences, 33, 61135. https://doi.org/10.1017/S0140525X0999152X.

Hofstede, G. H. (2001). Culture's consequences: Comparing values, behaviors, institutions, and organizations across nations (2nd ed.). Beverly Hills: Sage Publications.

Kağıtçıbaşı, C. (2003). Autonomy, embeddedness and adaptability in immigration contexts. Human Development, 46, 145-150. https://doi.org/10.1159/000068584.

Kağıtçıbaşı, C. (2007). Family, self, and human development across cultures: Theory and applications (2nd ed.). Mahwah: Erlbaum.

Kiang, L., Merçon-Vargas, E. A., Mendonça, S. E., Payir, A., \& O’Brien, L. (2018). The development of gratitude and its relation to spending preferences and materialism. In J. 
R. H. Tudge \& L. B. L. Freitas (Eds.), Developing gratitude in children and adolescents (pp. 154-173). London: Cambridge University Press.

Kristjánsson, K. (2013). An Aristotelian virtue of gratitude. Topoi. https://doi.org/10.1007/s11245-013-9213-8.

La Taille, Y. (2000). Para um estudo psicológico das virtudes morais. Educação e Pesquisa, 26, $109-122$.

La Taille, Y. (2018). Towards a psychological study of the virtues. In J. R. H. Tudge \& L. B. L. Freitas (Eds.), Developing gratitude in children and adolescents (pp. 25-41). London: Cambridge University Press.

Liang, Y., \& Kiang, L. (2018). Expressions of gratitude, wishes, and spending preferences among Chinese children and adolescents. Cross-Cultural Research, 52(1), $73-$ 86. https://doi.org/10.1177/1069397117737236.

McConnell, T. (1993). Gratitude. Philadelphia: Temple University Press.

McCullough, M. E., Emmons, R. A., \& Tsang, J. A. (2002). The grateful disposition: A conceptual and empirical topography. Journal of Personality and Social Psychology, 82, 112-127. https://doi.org/10.1037//0022-3514.82.1.112.

Merçon-Vargas, E. A. (2017). Children's expressions of gratitude and their association with cultural values among Brazilians, Brazilians in the U. S., and U.S. ethnic groups (Doctoral dissertation). NC Digital Online Collection of Knowledge and Scholarship (NCDOCKS). Greensboro, NC: University of North Carolina at Greensboro.

Mendonça, S. E., Merçon-Vargas, E. A., Payir, A., \& Tudge, J. R. H. (2018). The development of gratitude in seven societies: Cross-cultural highlights. Cross-Cultural Research, 52(1), 135-150. https://doi.org/10.1177/1069397117737245.

Merçon-Vargas, E. A., Pieta, M. A. M., Freitas, L. B. L., \& Tudge, J. R. H. (2016). The wishes and gratitude of students from private and public schools. Psico-USF, 21, 651662. https://doi.org/10.1590/1413-82712016210317.

Merçon-Vargas, E. A., Poelker, K., \& Tudge, J. R. H. (2018). The development of the virtue of gratitude: Theoretical foundations and cross-cultural issues. Cross-Cultural Research, 52(1), 3-18. https://doi.org/10.1177/1069397117736517.

Morgan, B., \& Gulliford, L. (2018). Assessing influences on gratitude experience: Age-related differences in how gratitude is understood and experienced. In J. R. H. Tudge \& L. B. L. Freitas (Eds.), Developing gratitude in children and adolescents (pp. 65-88). London: Cambridge University Press.

Nelson, J. A., Freitas, L. B. L., O’Brien, M., Calkins, S. D., Leerkes, E. M., \& Marcovitch, S. (2013). Preschool-aged children's understanding of gratitude: Relations with emotion and mental state knowledge. British Journal of Developmental Psychology, 31, 4256. https://doi.org/10.1111/j.2044-835X.2012.02077.x. 
Nielsen, M., Haun, D., Kärtner, J., \& Legare, C. H. (2017). The persistent sampling bias in developmental psychology: A call to action. Journal of Experimental Child Psychology, 162, 31-38. https://doi.org/10.1016/j.jecp.2017.04.017.

O’Brien, L., Mendonça, S. E., \& Price, U. S. (2018). The development of gratitude in the United States. Cross-Cultural Research, 52(1), 5872. https://doi.org/10.1177/1069397117737053.

Navarro, J. L., \& Morris, H. (2018). Defining gratitude: A theoretical and methodological review of research with children and adolescents. Poster presentation at SRCD Character Development Special Topic Meeting, Philadelphia, PA.

Palhares, F., Freitas, L. B. L., Merçon-Vargas, E. A., \& Tudge, J. R. H. (2018). Gratitude and materialism among Brazilian children and adolescents. Cross-Cultural Research, 52(1), 31-43. https://doi.org/10.1177/1069397117736749.

Piaget, J. (1965). The moral judgement of the child. New York: Free Press. (Original published in 1932).

Piaget, J. (1995). Sociological studies. Genève: Droz. (Original published in 1965).

Piaget, J., \& Inhelder, B. (1969). The psychology of the child. New York: Basic Books. (Original published in 1966).

Poelker, K. E., \& Gibbons, J. L. (2018). The development of gratitude in Guatemalan children and adolescents. Cross-Cultural Research, 52(1), 4457. https://doi.org/10.1177/1069397117736518.

Poelker, K. E., Gibbons, J. L., Maxwell, C. A., \& Elizondo-Quintanilla, I. L. (2017). Envy, gratitude, and well-being among Guatemalan adolescents with scarce economic resources. International Perspectives in Psychology: Research, Practice, Consultation, 6, 209-226. https://doi.org/10.1037/ipp0000076.

Prestes, A. C., Castro, F. M. P., Tudge, J. R. H., \& Freitas, L. B. L. (2014). Desenvolvimento de valores em crianças e adolescentes. Leopoldianum, 40, 25-36.

Prinz, J. (2009). The normativity challenge: Cultural psychology provides the real threat to virtue ethics. The Journal of Ethics, 13, 117-144. https://doi.org/10.1007/s10892-009-9053-3.

Ramsey, M. A., Gentzler, A. L., \& Vizy, B. (2018). Children's and parents' understanding of gratitude. In J. R. H. Tudge \& L. B. L. Freitas (Eds.), Developing gratitude in children and adolescents (pp. 220-239). London: Cambridge University Press.

Roberts, C. R. (2016). Gratitude and humility. In D. Carr (Ed.), Perspectives on gratitude: An interdisciplinary approach (pp. 57-69). New York: Routledge.

Stein, G. L., Cupito, A., Mendez, J. L., Prandoni, J., Huq, N., \& Westerberg, D. (2014). Familism through a developmental lens. Journal of Latina/o Psychology, 2, 224 250. https://doi.org/10.1037/lat0000025.

Tiberius, V. (2004). Cultural differences and philosophical accounts of well-being. Journal of Happiness Studies, 5, 293-314. https://doi.org/10.1007/s10902-004-8791-y. 
Tudge, J. R. H. (2008). The everyday lives of young children: Culture, class, and child rearing in diverse societies. New York: Cambridge University Press.

Tudge, J. R. H., Freitas, L. B. L., Mokrova, I. L., Wang, Y. C., \& O’Brien, M. (2015a). Children's wishes and their expression of gratitude. Paidéia, 25, 281288. https://doi.org/10.1590/1982-43272562201501.

Tudge, J. R. H., Freitas, L. B. L., \& O'Brien, L. T. (2015b). The virtue of gratitude: A developmental and cultural approach. Human Development, 58, 281300. https://doi.org/10.1159/000444308.

Tudge, J. R. H., Hogan, D. M., Snezhkova, I. A., Kulakova, N. N., \& Etz, K. E. (2000). Parents' child-rearing values and beliefs in the United States and Russia: The impact of culture and social class. Infant and Child Development, 9, 105-121.

Visser, M. (2009). The gift of thanks: The roots and rituals of gratitude. Boston: HoughtonMifflin.

Wang, D., Wang, Y. C., \& Tudge, J. R. H. (2015). Expressions of gratitude in children and adolescents: Insights from China and the United States. Journal of Cross-Cultural Psychology, 46, 10-39. https://doi.org/10.1177/0022022115594140. 